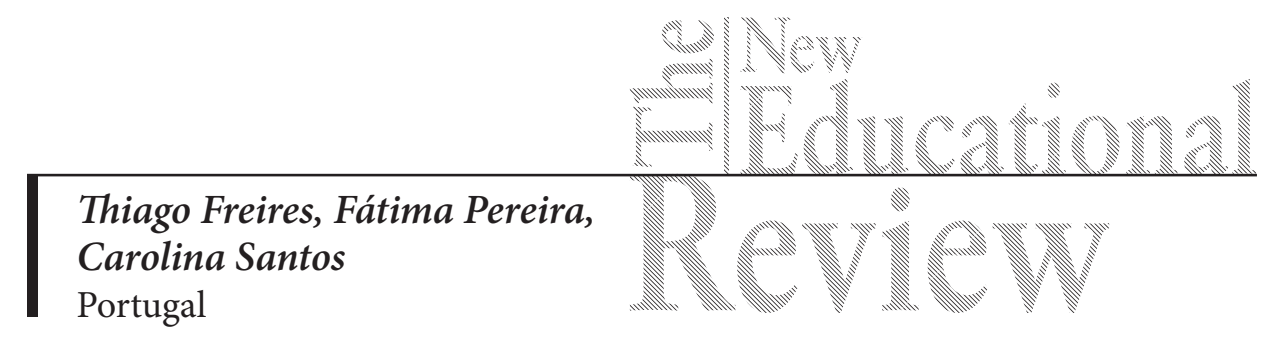

\title{
Family Involvement in Schooling. A North Portugal Portrait by Elementary Students
}

DOI: 10.15804/tner.2016.44.2.04

\begin{abstract}
Family involvement in education is highlighted as a key factor to boost students' success. In this paper, we analyze ninth-graders' discourses on how they see family participation in school-related activities. Data derive from 38 biographical interviews involving students from eight public schools from North Portugal. Following a narrative approach, findings emphasize that active involvement of parents make up a fundamental dimension for the consolidation of educational projects. Data reveal that mothers play a leader role in the educational setting, while fathers' lack of participation can impact negatively on students' trajectories. In addition, research indicates that an extended family can emerge as crucial to the maintenance of a schooling project.
\end{abstract}

Keywords: family involvement, parental involvement, schooling trajectories, narratives

\section{Introduction - On parental and family involvement in school}

The perception of youth about their educational processes, as well as the way in which they relate to school, is directly influenced by the way parents and families deal with educational institutions (Denessen, Hornstra and Van Den Bergh, 2010). Recent studies have found out that family engagement in schooling processes can boost the academic and identity development of students in a positive way (Hall 
and Callery, 2003; McBride, Schoppe-Sullivan and Ho, 2005; Schlee, Mullis and Shriner, 2009; Fan and Williams, 2010; Antonopoulou, Koutrouba and Babalis, 2011; Wilder, 2013).

The literature has addressed family involvement in school-related activities in two main perspectives. On the one hand, there is an interest in understanding how the results obtained by students correspond to family socialization. On the other one, focus lies on the relationship of achievements with socioeconomic matters. Methodological procedures applied in this field vary from interviewing parents to analyzing school records. In our work, the emphasis is on the feelings students have concerning their parents' and relatives' involvement in their educational trajectories along the years. Thus, following a qualitative approach, our findings emerge from the interpretation of how students themselves organize their families' conception and influences in terms of the schooling experience.

Prior knowledge of factors that influence the organization of relations between family and school, mediated by the trajectory of the student in these two fields, is elementary in the identification of the effects that can be patterned in the youths' history. According to McBride, Schoppe-Sullivan and Ho (2005), the main mediators between academic development and family involvement are race and ethnic origin, the level of parents' education, mothers' involvement in the labor market, socioeconomic status, students' age, characteristics and policies of the school, as well as teachers' own practices. Additionally, our analysis also took into consideration the family's previous achievements and aspirations and expectations that parents have about the educational trajectory of their children (Spera, Wentzel and Matto, 2009; Fan and Williams, 2010; Wilder, 2013).

Despite the fact that families are arranged in various ways (Schlee, Mullis and Shriner 2009), it is still believed that the father has an immediate impact on the child's trajectory. McBride, Schoppe-Sullivan and Ho (2005) claim that although fathers had always been considered in subordination to mothers when debating involvement in school education, data emerging from the field show that they are able to have a positive impact on the education and growth of their children, if actively involved in their educational processes.

Lahire (1997) infers that a plausible explanation of the variability of youth trajectories and the differences regarding the achievement of success at school may reside in the association of private dynamics (family character) to the public ones (school related). It is in this direction that Fan and Williams (2010) discuss how the communication between school and parents can be reflected in practical results regarding the schooling trajectory. The authors draw attention to the fact that the school communication with the family tends to reproduce patterns of its 
origins. Then, if it starts on good grounds, in the debate of everyday activities, it has more chances to flourish.

A final aspect concerning the role of the family and its projections in the educational field has to do with intergenerational accomplishment. Singly (2007) refers to the idea that parents reveal a feeling that school is very important, although they cannot explain why, and express the hope that their children achieve a level of education higher than theirs. For him, the investment and strategies families make use of to keep their children at school are motivated by the achievement of a degree, a process that can result in a bargaining value in the labor market. Such a view is centered on the utilitarian perspective of school. It can be confronted, though, with the idea that making children reach higher levels of education is part of a family project, whose roots can be traced generations back.

\section{Method}

Data was collected in partnership with the Observatory of Life in Schools (OBVIE) belonging to the Centre for Research and Intervention in Education (CIIE) of the Faculty of Psychology and Educational Sciences of the University of Porto (FPCEUP). Implemented in 2008, the Observatory maintains active partnership with sixteen school clusters in North Portugal. Eight of them participated in our research.

Interested in particular forms and logics by which students build and attribute meaning to their educational trajectories, we chose the biographical approach (Goodson, 2013) as a suitable method. In this context, biographical interviews emerged as instruments due to their potential to narrate diverse tenses, allowing for putting the subjects' experiences and desires in a socio-historical context (Pereira, 2011).

Executed in two years, the project on schooling effects involved two stages. At the first one, thirty-four biographical interviews were collected from $9^{\text {th }}$ grade students, aged between 14 and 16. Selection considered criteria such as gender, social and academic background. After the systematization of the material, there was a second round of data collection, aimed at deepening and providing greater consistency to the issues identified as relevant in the study. Then, four out of the thirty-four interviewees participated in new meetings. The choice of these students was based on the identification of a binary behavior. Some of them depicted school as part of their life project and others believed the institution was not representative of their personal aspirations. Content analysis was used for the reading and interpretation of the material (ibid.). 


\section{Building an educational project: a word on drivers and barriers}

Findings reflect the dichotomy identified in the collected information. On the one hand, we framed the students' narratives that considered the family as a barrier to the development of a school/academic project. On the other one, we grouped the narratives that allowed for the consideration of the family as an entity of investment and support for school-related activities.

With regard to family involvement in school, despite the centrality of the role of parents, data point to siblings as a great influence. Similarly, cousins are reported as relatives with whom one can study together and benefit from homework support. These relationships are considered as positive and important, as the ones established with friends who help to give cohesion and motivation to study.

Establishing a social network at school can be facilitated when other family members go to the same institution, especially cousins. To some extent, the development of these relationships inside and outside of school minimizes the effects of parental absence and bridges the gap in the role of family concerning education. These relatives, usually older, not only have potential to replace a parental figure in the context of education, but also to make up one, when none is found.

It was clear from the interviews that mostly mothers are in charge of educational matters. According to the students, the family member who supports them is usually the one who has more free time to go to school. In this sense, mothers continue to fulfill the role. Interestingly, the reports point to the fact that when both parents carry out professional activity without flexible character, the mothers remain as the first choice for being the education guardian. In this sense, it is highlighted that fathers' involvement in school is lower when compared to mothers'.

For a considerable number of the students, the father figure is usually absent. Some fathers are working abroad and others do not come regularly after divorce. Whatever the case, these situations concern the important factor of the influence on how young students perceive their school trajectories (Glick and Sahn 1998; Rogers, Wiener, Marton and Tannock 2009; Ross and Mirowsky 2011). For the minority, it justifies the beginning of an institutional denial, in which school emerges as a non-important place. Little by little, they quit getting involved in its activities, rules and routines.

A group of students addresses parents and their school involvement as a more rigorous process. Although these parents face constraints, they are participative. These students mention parental involvement in activities other than school meetings. Occasions such as parties, award celebrations or class councils, moments that are displayed as fundamental mediators of how young students organize 
their conception of school and its importance in their personal lives (McBride, Schoppe-Sullivan and Ho, 2005). In addition, these events reveal the kind of openness schools present when it comes to their relationship with parents and relatives. Clearly, the parents' participation in these activities benefits the way young people understand the school culture.

Communication between the parents and the teachers is deficient, though the majority of the parents demonstrate support to the way the teachers run their activities. Respecting the teachers, as we can infer, is a collaborative construction between families and school practices and discourses. In most cases, the parents' relationship with school is mediated exclusively by their children's achievements, an issue of relevance for them. School, in mediations of this kind, presents itself as essential and unquestionable, including the speech of those parents who cannot or are not willing to adhere to school practices. Our research corroborates the argument that families, regardless of their sociocultural conditions, still recognize meaning and value in schoolwork (Lahire, 1997; Singly, 2007).

The analysis of data enabled us to emphasize and deploy features identified as crucial in the relationship between the family and the school. Rather than demonstrating that absence can increase deviant behaviors (McBride, Schoppe-Sullivan and Ho, 2005), the narratives highlighted the act of investing resources as a catalyst of the youth's personal goals. This becomes explicit from the narratives centered on the parents' efforts to provide a quality education, through the commitment of ensuring tools for learning, like books and computers, and granting other learning experiences, e.g., language courses and sports.

Responding to the family's material and emotional investment, from the perspective of the student, means setting long-term goals for the educational trajectory and corresponding to the parental effort by demonstrating commitment to school. The investment/lack of investment factor is a key one in interpreting the conception the young students have about their educational trajectories. Data analysis led us to the conclusion that the weight of the responsibilities concerning school activities relates to the value that the parents attach to practices, as well as the support that they provide - not exclusively financially. A character that can be determinant of how students perceive school experiences and a solid explanation of the existing discrepancies among different youth trajectories (Barbosa, 2007).

In the case of learning through striking episodes in the family context, reports stress their potential to influence the youth's constant (re)organization of the world. Thus, some cases like the mother who went through a depression period, the father who moved to France for professional reasons, contribute to the students' maturity and to their review of concept meanings. In this way, absence becomes 
support, rebellion transforms into affection and what was supposedly a negative change encourages the acceptance of new roles, which contributes to improving the quality of family relationships. This reorganization of interactions, in some cases, causes the emergence of a new attitude towards the learning processes (Lahire, 1997).

Data does not allow us to present a fair socioeconomic assessment of the families involved in the project, but the narratives provide the main tones of this scenario. There are reports of unemployed parents, some of them emigrated in search of work, and many students, when reflecting on their future, refer to the financial aspect as a barrier for their projects. In this sense, the effort to remain at school seems to be reversely proportional to the parents' level of education. One might observe that in Portugal there is still quite high dropout before secondary education (Magalhães, 2008).

In terms of family resources availability and social capital mobilization, we observed that the youth assume their parents' and relatives' trajectories as models to be overcome collectively (Spera, Wentzel and Matto, 2009; Fan and Williams 2010; Wilder, 2013). In general, there is consensus that the mothers and fathers had given up schooling due to financial conditions and, also, for the enhancement of the family project. Accordingly, the narrative of a participant of our second phase illustrates this idea of assuming a previous family schooling trajectory as a driving force for the settlement of a new project. For the student, the fact that only one aunt among sixteen uncles and aunts had the chance to access higher education is the cause of investment on the part of his parents and relatives. Together, they are focused on helping him make it to college, a project he is willing to achieve.

Not all the students' trajectories in our research are centered on school as a life driver, though. The narratives reveal the youth who gradually disengage from school and its dynamics, building their trajectories on the basis of indiscipline, absenteeism and negative grades. These students report conflict situations in the family scenario and have great difficulties in communication with their parents. At school, they work as little as possible and achievements are seen as a result of facilitated processes. Along time, such trajectories might take new contours (Charlot, 2009).

One of our second phase participants illustrates the transformation throughout time scenario. It was the entrance to secondary school, in a course aimed at vocational training, which helped him rethink the meaning of education. At home, he says, relationships are becoming better. There is no more spanking, although he does not feel much interested in school activities. His grades have improved, but he finds it hard to get motivated. 


\section{Final considerations}

The presented research strengthens the idea that the involvement of parents in the educational processes and the adherence of other family members in supporting the students' construction of a schooling trajectory are fundamental to empowering their projects. According to the degree of involvement, which can be identified by mediators previously mentioned, the students rearrange the way they perceive themselves and what they think of school.

Findings suggest that the participation of the family in the educational processes can influence the trajectories towards greater homogeneity between the two institutions, family and school, especially with regard to the individual's primary socialization. Accordingly, such a dialogue can promote conditions for a successful livelihood in both contexts, private and public. The dichotomy of subjects who adhere to school logics or deny it should not be read immediately in line with a higher or lower family appreciation of educational processes, however. The patterns that underpin a greater adherence to school logics are influenced by the family world and the passage of time (Charlot, 2000; Barbosa, 2007). Students' attitude in relation to school is, sometimes, prior to the way the family integrates within this universe. In fact, the primary attitude of students concerning school is often what triggers - or not - family processes of participation in the context of formal education.

Mediators of the family-school relationship that proved to have more impact relate to the participation of the parents in meetings, monitoring of activities carried out in the family context and the interest of the family members in the student's school life, not represented by the demand for good grades, but by a desire to debate everyday life experiences. Social capital and economic investment have proved less relevant than the consideration of emotional support for the implementation of the educational project (Magalhães, 2012). The confrontation with a diversity of educational trajectories can be justified by how students perceive the intersection of their parents and relatives' expectations with their desired project.

Mothers continue having the lead role in terms of education, even when engaged in the labor market whereas fathers, from the perspective of the students, show little interest in their children's schooling trajectories. The role of the father, as the students see it, has been restricted to the demand of results, keeping them apart from children, and prompting negative attitudes towards school life. The students clearly feel the absence of their fathers and desire to resume the relationship with them (Glick and Sahn, 1998; McBride, Schoppe-Sullivan and Ho, 2005). The narratives show the students want their fathers to get involved in the areas 
where they traditionally have had little participation, as homework assistance and parent-teacher meetings.

The importance of school prevails in social discourse (Lahire, 2006; Singly, 2007). Even less participative parents support their children's development of a school project, either for reasons of obligation or by the idea of sharing a project. In the process of schooling, it is worth noting that the degree of autonomy granted by parents to their children is determinant of how the family's dialogue with school can develop. This study shows that the students are not willing to enjoy full freedom regarding the management of their school trajectory. In this aspect, they question and feel unprotected when their parents do not require any kind of responsibility. In the same way, they appreciate that, gradually, the parents make concessions in terms of autonomy.

One of the main differences of this study in relation to others focused on the theme of family involvement in the educational processes lies in the use of the narrative approach. In this sense, this article presents how students set out their trajectories and the way in which they believe parents and relatives can help or not - to make up a school-oriented life project. Interpretation evolves from youth's perception with a high interest in the interactive perspective of elements composing a schooling trajectory. Given the research dimensions, its choices and constraints, we emphasize that the presented results portray features of individual and unique character, characteristic of a specific setting, the North of Portugal.

\section{References}

Antonopoulou, K., Koutrouba, K., and Babalis, T. (2011). "Parental Involvement in Secondary Education Schools: The Views of Parents in Greece." Educational Studies 37(3): 333-344. doi: 10.1080/03055698.2010.506332

Barbosa, M.C.S. (2007). “Culturas Escolares, Culturas de Infância e Culturas Familiares: As Socializações e a Escolarização no Entretecer destas Culturas” [School Culture, Childhood Culture and Family Culture: The Socializations and Schooling in the Interweave of These Cultures]. Educação e Sociedade 28 (100): 1059-1083. http://www.redalyc.org/ articulo.oa? $\mathrm{id}=87313704020$

Charlot, B. (2000). Da Relação com o Saber: Elementos para uma Teoria [Attitude to Knowledge: Elements of a Theory]. Porto Alegre: Artmed Editora.

Charlot, B. (2009). A Relação com o Saber nos Meios Populares: Uma Investigação nos Liceus Profissionais de Suburrbio [Attitude to Knowledge in Poor Contexts: Research at Professional Secondary Schools in the Suburbs]. Porto: CIIE /Livpsic.

Denessen, E., Hornstra, L., \& Van Den Bergh, L. (2010). "What is on our children`s minds? 
An analysis of children's writings as reflections of group-specific socialization practices." Educational Studies 36(1), 73-84. doi: 10.1080/03055690903148647

Fan, W., C.M. Williams. (2010). "The Effects of Parental Involvement on Students' Academic Self-Efficacy, Engagement and Intrinsic Motivation.” Educational Psychology: An International Journal of Experimental Educational Psychology 30 (1): 53-74. doi: 10.1080/01443410903353302.

Glick, P., and D.E. Sahn. (1998). "Schooling of Girls and Boys in a West African Country: The Effects of Parental Education, Income, and Household Structure." Economics of Education Review 19 (2000): 63-87. http://directory.umm.ac.id/Data\%20Elmu/jurnal/E/ Economics\%20of\%20Education\%20Review/Vol19.Issue1.Feb1999/337.pdf

Goodson, I.F. 2013. Developing Narrative Theory: Life Histories and Personal Representation. London: Routledge.

Hall, W.A., and P. Callery. (2003). "Balancing Personal and Family Trajectories: An International Study of Dual-Earner Couples with Pre-School Children.” International Journal of Nursing Studies 40: 401-412. doi: 10.1177/1074840706297588.

Lahire, B. (1997). Sucesso Escolar nos Meios Populares: As Razões do Improvável [School Success in Poor Neighborhoods: The Improbable Reasons]. São Paulo: Ática.

Lahire, B. (2006). A Cultura dos Indivíduos [The Subjects Culture]. Porto Alegre: Artmed. Magalhães, Dulce. 2008. "Escola e Escolaridade no Norte de Portugal: Práticas em Mudança [School and Schooling in North Portugal: Changing Practices].” In A Região Norte de Portugal: Mudanças e Continuidades na Contemporaneidade [North Region of Portugal: Contemporary Changes and Continuities], edited by Carlos M. Gonçalves, 1-62. Porto: Instituto de Sociologia da Faculdade de Letras do Porto.

Magalhães, D. (2012). "The Habitus and the New: From Social (re)learning to Practices. Revista Latina de Sociologia 2: 23-41.

McBride, B.A., S. Schoppe-Sullivan, and M.Ho. 2005. “The Mediating Role of Fathers' School Involvement on Student Achievement." Applied Developmental Psychology 26: 201-216. doi: 10.1016/j.appdev.2004.12.007

Pereira, F. (2011). Referencial Teórico para o Projecto "Sentidos e Significados da Vida na Escola: Um Estudo Exploratório em Vozes do/a Aluno/a”. Porto: CIIE.

Rogers, M.A., J. Wiener, I. Marton, and R. Tannock. (2009). "Parental Involvement in Children's Learning: Comparing Parents of Children with and without Attention-Deficit / Hyperactivity Disorder (ADHD)." Journal of School Psychology 47 (2009): 167-185. doi: 10.1016/j.jsp.2009.02.001.

Ross, C.E., J. Mirowsky, J. (2010). “The Interaction of Personal and Parental Education on Health." Social Science and Medicine 72 (2011): 591-599. doi: 10.1016/j. socscimed.2010.11.028.

Schlee, B.M., A.K. Mullis, and M. Shriner. (2009). "Parents Social and Resource Capital: Predictors of Academic Achievement during Early Childhood." Children and Youth Services Review 31: 227-234. doi: 10.1016/j.childyouth.2008.07.014.

Singly, F. (2007). Sociologia da Família Contemporânea [Contemporary Family Sociology]. Rio de Janeiro: FGV. 
Spera, C., K.R. Wentzel, and H.C. Matto. (2009). “Parental Aspirations for Their Children's Educational Attainment: Relations to Ethnicity, Parental Education, Children's Academic Performance, and Parental Perceptions of School Climate." Journal of Youth Adolescence 38: 1140-1152. doi: 10.1007/s10964-008-9314-7.

Wilder, S. (2013). "Effects of Parental Involvement on Academic Achievement: A Meta-Synthesis.” Educational Review 66(3): 1-21. doi: 1080/00131911.2013.780009 